\title{
Tribute to Richard S. Laskin, MD, 1940-2008
}

\author{
Thomas P. Sculco MD, Richard A. Brand MD
}

Published online: 29 August 2008

(C) The Association of Bone and Joint Surgeons 2008

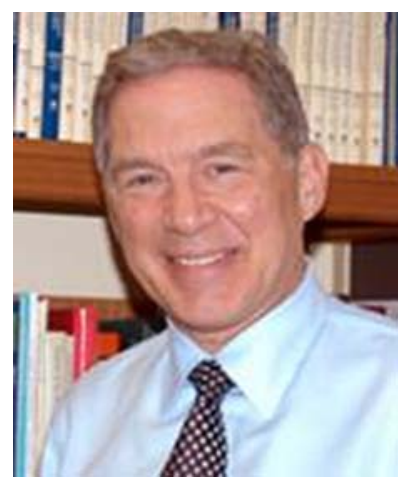

Dr. Richard Laskin is shown.

Dr. Richard S. Laskin grew up in Brooklyn, New York, the first in his family to attend either college or medical school. He was a brilliant student and accelerated through college at Hofstra University, graduating in 1960, and then receiving his medical degree from New York University College of Medicine in 1964. He did his residency at Albert Einstein College of Medicine. He subsequently served in Viet Nam in the U. S. Army and received a number of decorations, including the Purple Heart for injuries received during a grenade attack. Dick was early on recognized as a leader in orthopaedic surgery and at a very young age became the Chief of Orthopaedic Surgery at the Long Island Jewish Hospital and residency program.

T. P. Sculco

Hospital for Special Surgery, New York, NY, USA

R. A. Brand $(\bowtie)$

Clinical Orthopaedics and Related Research, 1600 Spruce Street, Philadelphia, PA 19103, USA

e-mail: dick.brand@clinorthop.org
Dick Laskin's great love in orthopaedic surgery was knee replacement surgery and he dedicated his career to improving implant design and techniques. He joined the staff at Hospital for Special Surgery in 1991 and his impact on the hospital was remarkable. He was a great teacher and mentor to residents, fellows and staff. A brilliant writer and a gifted speaker, Dick Laskin would learn the language of the country in which he was speaking and give presentations in Spanish, Italian, Japanese and Chinese. His talks were always filled with much knowledge as well as humor, and inevitably cartoons flew in and out of the presentations.

Dr. Laskin was active in the Knee Society and served as its Program Director on several occasions and on its Board of Directors. In 1997 he became Deputy Editor for The Knee Society at Clinical Orthopaedics and Related Research, a post he held and expertly fulfilled until 2007. In 2004 he became the first Editor of the HSS Journal and established it as an outstanding peer-reviewed musculoskeletal publication. He was the force behind its success and his presence was felt in every aspect of the journal. He was also Director of the Arthroplasty Service at HSS, and received the Lifetime Achievement Award from Hospital for Special Surgery posthumously in June 2008.

The two articles we reproduce here reflect his commitment to documenting outcomes of new approaches. The first reflects an early followup of a new approach to treating knee arthrosis: modular total knee-replacement arthroplasty [1]. The series was relatively large (58 patients with osteoarthritis and 31 with rheumatoid arthritis), and so would certainly serve to identify early complications (of which there were relatively few) and to raise a question as to whether the approach actually improved ROM and stair climbing. The second reflects the sort of longer-term followup to which Dr. Laskin was 
committed [2]. In a series of 80 total condylar arthroplasties in rheumatoid arthritis, a challenging group in those days when most patients had severe disease, Dr. Laskin demonstrated a $75 \%$ survival at 10 years. Of note is both of these articles were authored solely by Dr. Laskin, a rarity these days, but a demonstration of his commitment and the long hours he worked.

Dick Laskin was passionate about everything he did. He loved model trains, electronic gadgets, opera, marathons, and his family. He was a giant among men, a truly good person who cared about his patients and committed his life to improving knee-replacement surgery.

\section{References}

1. Laskin RS. Modular total knee-replacement arthroplasty. A review of eighty-nine patients. J Bone Joint Surg Am. 1976;58:766-773.

2. Laskin RS. Total condylar knee replacement in patients who have rheumatoid arthritis. A ten-year follow-up study. J Bone Joint Surg Am. 1990;72:529-535. 